\title{
Pengaruh Kebisingan terhadap Ambang Pendengaran Karyawan Arena Bermain
}

\author{
Cintia P. Septianingsih, ${ }^{1}$ Ora Et Labora I. Palandeng, ${ }^{2}$ Olivia C. P. Pelealu ${ }^{2}$
}

\author{
${ }^{1}$ Program Studi Pendidikan Dokter Fakultas Kedokteran Universitas Sam Ratulangi Manado \\ ${ }^{2}$ Bagian THT-KL Fakultas Kedokteran Universitas Sam Ratulangi Manado \\ Email: tiwicintia@gmail.com
}

\begin{abstract}
Noise at a certain level and time can cause human health problems and environmental discomfort. These conditions occur if the noise intensity exceeds the threshold level related to time and place. This study was aimed to obtain the influence of noise intensity at work to hearing disturbance among the employees of game arenas. This was an analytical study with a cross-sectional design. Data were obtained by questionnaire filling, noise measurement by using a sound level meter, physical examination, and auditory function examination by using audiometry and then were analyzed by using the Fisher exact test. There were three game arenas in this study, as follows: Amazing Zone Star Square Manado, Amazone, and Timezone Manado Town Square. The results showed that there were 18 respondents in this study. The mean noise intensity at the game arenas were $85.5 \mathrm{dBA}$ at Timezone, $89.8 \mathrm{dBA}$ at Amazone, and $85.4 \mathrm{dBA}$ at Amazing Zone. Hearing disturbance was found ian $72 \%$ of the total employees. The Fisher exact test showed a $p$-value of 0.294 ( $p>0.05)$ for the influence of noise intensity to hearing disturbance. In conclusion, the noise intensity at the game arenas did not affect the hearing threshold of the game arena employees.
\end{abstract}

Keywords: noise, hearing threshold, playing area employees

\begin{abstract}
Abstrak: Kebisingan dalam tingkat dan waktu tertentu dapat menimbulkan gangguan kesehatan manusia dan kenyamanan lingkungan. Hal ini terjadi jika intensitas bising melebihi nilai ambang batas yang ditetapkan berdasarkan waktu dan tempat. Penelitian ini bertujuan untuk mendapatkan hubungan antara intensitas kebisingan di tempat kerja dengan gangguan fungsi pendengaran pada karyawan arena bermain. Jenis penelitian ialah analitik dengan desain potong lintang. Data diperoleh melalui pengisian kuisioner, pengukuran kebisingan dengan sound level meter, pemeriksaan fisik, dan pemeriksaan fungsi pendengaran dengan audiometri. Analisis data menggunakan uji Fisher exact. Terdapat 3 arena bermain yang diikutsertakan dalam penelitian ini, yaitu: Amazing Zone Star Square Manado, Amazone, dan Timezone Manado Town Square. Hasil penelitian mendapatkan intensitas kebisingan arena bermain sebagai berikut: Timezone 85,5 dBA, Amazone 89,8 dBA, dan Amazing Zone 85,4 dBA. Gangguan pendengaran didapatkan pada $72 \%$ dari total responden. Hasil uji Fisher exact mendapatkan nilai $\mathrm{p}=0,294$ $(p>0,05)$ untuk pengaruh kebisingan terhadap gangguan pendengaran. Simpulan penelitian ini ialah kebisingan di arena bermain tidak memengaruhi ambang pendengaran karyawan arena bermain.
\end{abstract}

Kata kunci: bising, ambang pendengaran, karyawan arena bermain

\section{PENDAHULUAN}

Kebisingan adalah bunyi yang tidak diinginkan dari usaha atau kegiatan dalam tingkat dan waktu tertentu yang dapat menimbulkan gangguan kesehatan manusia dan kenyamanan lingkungan. ${ }^{1}$ Hal ini terjadi jika intensitas bising melebihi nilai ambang batas yang ditetapkan berdasarkan waktu dan tempat. $^{2}$

Gangguan pendengaran bersifat se- 
mentara yang disebabkan pajanan bising intensitas tinggi dalam waktu singkat dan bersifat menetap disebabkan pajanan bising intesitas tinggi dalam waktu lama. Noise illness hearing loss (NIHL) merupakan gangguan pendengan yang disebabkan oleh kebisingan dan didefinisikan sebagai penurunan permanen pada tingkat ambang pendengaran. ${ }^{3}$ Arena bermain khususnya Amazing Zone, Amazone, dan Timezone merupakan tempat rekreasi anak yang paling diminati untuk mengisi agenda liburan keluarga di Kota Manado. Hal tersebut dapat menambah risiko bahaya paparan kebisingan dari mesin permainan. ${ }^{4}$

Pada survei WHO tahun 2000 diperkirakan 250 juta $(4,2 \%)$ penduduk dunia menderita gangguan pendengaran dan 75 sampai 140 juta di Asia Tenggara. Hasil pertemuan WHO SEARO intercountry Consultation Meeting tahun 2002 di Colombo, Sri Langka memrioritaskan masalah yang harus ditangani dan salah satunya ialah tuli akibat pajanan bising (NIHL). ${ }^{5}$ Penelitian pada tahun 2014 di Timezone dan Amazone Manado Town Square mendapatkan rerata kebisingan sebesar $88 \mathrm{~dB}$ dan $93 \mathrm{~dB}$ serta terdapatnya hubungan antara kebisingan, lama bekerja dan ambang pendengaran pada karyawan. ${ }^{4}$ Penelitian pada tahun 2015 di Game Central Area di Manado Town Square melaporkan bahwa kebisingan di tempat tersebut telah di atas nilai ambang pendengaran dan terdapatnya hubungan antara kebisingan dan fungsi pendengaran para karyawan. ${ }^{6}$

Berdasarkan latar belakang ini maka peneliti tertarik untuk mengetahui pengaruh kebisingan terhadap ambang pendengaran karyawan di arena bermain.

\section{METODE PENELITIAN}

Penelitian ini dilakukan pada tiga arena bermain, yaitu Amazing Zone Star Square Manado, Amazone, dan Timezone Manado Town Square. Jenis penelitian yang digunakan ialah analitik dengan desain potong lintang. Populasi penelitian ini ialah semua karyawan Amazing Zone Star Square
Manado, Amazone, dan Timezone Manado Town Square.

Penelitian ini telah mendapat persetujuan dari Komisi Etik Penelitian Kesehatan RSUP Prof. Dr. R. D. Kandou Manado, dengan nomor keterangan layak etik yaitu No. 080/EC/KEPK-KANDOU/XI/2019.

\section{HASIL PENELITIAN}

Pada penelitian ini terdapat 18 orang karyawan arena bermain yang menjadi responden penelitian terdiri dari 13 orang laki-lai dan 5 orang perempuan. Menurut tempat kerja didapatkan 4 orang laki-laki dari Amazing Zone Star Square Manado, 4 orang laki-laki dan 3 orang perempuan dari Amazone Manado Town Square, dan 5 orang laki-laki dan 2 orang perempuan dari Timezone Manado Town Square.

Tabel 1 memperlihatkan distribusi responden menurut usia. Responden terbanyak berusia $18-21$ tahun (56\%) dan yang paling sedikit ialah berusia $>30$ tahun, yaitu sebanyak 1 orang $(6 \%)$.

Tabel 1. Distribusi responden menurut usia

\begin{tabular}{ccc}
\hline $\begin{array}{c}\text { Usia } \\
\text { (tahun) }\end{array}$ & Jumlah & Persentase \\
\hline $18-21$ & 10 & 56 \\
$22-30$ & 7 & 38 \\
$>30$ & 1 & 6 \\
Total & 18 & 100 \\
\hline
\end{tabular}

Tabel 2 memperlihatkan responden yang bekerja $<10$ tahun sebanyak 17 orang (94\%) dan yang bekerja $\geq 10$ tahun sebanyak 1 orang $(6 \%)$.

Tabel 2. Distribusi responden menurut lama kerja

\begin{tabular}{ccc}
\hline Lama kerja & Jumlah & Persentase \\
\hline$<10$ tahun & 17 & 94 \\
$\geq 10$ tahun & 1 & 6 \\
Total & 18 & 100 \\
\hline
\end{tabular}

Tabel 3 memperlihatkan responden yang memiliki durasi kerja 8 jam sebanyak 15 orang $(83 \%)$ dan yang memiliki durasi kerja 12 jam sebanyak 3 orang (17\%). 
Tabel 4 memperlihatkan bahwa responden yang terpapar kebisingan $<85 \mathrm{~dB}$ selama bekerja sebanyak 9 orang $(50 \%)$ dan yang terpapar kebisingan $\geq 85 \mathrm{~dB}$ selama bekerja sebanyak 9 orang $(50 \%)$.

Tabel 3. Distribusi responden menurut durasi kerja

\begin{tabular}{ccc}
\hline Durasi kerja & Jumlah & Persentase \\
\hline 8 jam & 15 & 83 \\
12 jam & 3 & 17 \\
Total & 18 & 100 \\
\hline
\end{tabular}

Tabel 4. Distribusi responden menurut tingkat kebisingan

\begin{tabular}{ccc}
\hline $\begin{array}{c}\text { Tingkat } \\
\text { kebisingan }\end{array}$ & Jumlah & Persentase \\
\hline$<85 \mathrm{~dB}$ & 9 & 50 \\
$\geq 85 \mathrm{~dB}$ & 9 & 50 \\
Total & 18 & 100 \\
\hline
\end{tabular}

Tabel 5 memperlihatkan bahwa responden yang memiliki meatus akustikus eksternus (MAE) normal sebanyak 18 orang $(100 \%)$; tidak terdapat responden yang memiliki MAE dengan serumen minimal.

Tabel 6 memperlihatkan bahwa responden yang memiliki membran timpani normal sebanyak 18 orang; tidak terdapat responden yang memiliki membran timpani perforasi maupun sikatriks.

Tabel 7 memperlihatkan hasil audiometri dari responden. Fungsi pendengaran normal pada telinga kanan didapatkan pada sebanyak 10 responden dan fungsi pendengaran normal pada telinga kiri sebanyak 8 responden. Jumlah responden yang memiliki tuli ringan pada telinga kanan 8 orang dan tuli ringan pada telinga kiri sebanyak 10 orang. Tidak didapatkan responden yang memiliki tuli sedang maupun tuli berat.

Tabel 5. Distribusi responden menurut kondisi fisik telinga untuk meatus akustikus eksternus (MAE)

\begin{tabular}{ccccc}
\hline \multirow{2}{*}{ MAE } & \multicolumn{2}{c}{ Dextra } & \multicolumn{2}{c}{ Sinistra } \\
& Jumlah & Persentase & Jumlah & Persentase \\
\hline Normal & 18 & 100 & 18 & 100 \\
Serumen & 0 & 0 & 0 & 0 \\
Total & 18 & 100 & 18 & 100 \\
\hline
\end{tabular}

Tabel 6. Distribusi responden menurut kondisi fisik telinga untuk membran timpani (MT)

\begin{tabular}{ccccc}
\hline MT & \multicolumn{2}{c}{ Dextra } & \multicolumn{2}{c}{ Sinistra } \\
& Jumlah & Persentase & Jumlah & Persentase \\
\hline Normal & 18 & 100 & 18 & 100 \\
Perforasi & 0 & 0 & 0 & 0 \\
Sikatriks & 0 & 0 & 0 & 0 \\
Total & 18 & 100 & 18 & 100 \\
\hline
\end{tabular}

Tabel 7. Distribusi responden menurut derajat ketulian berdasarkan hasil audiometri

\begin{tabular}{ccccc}
\hline Hasil & \multicolumn{2}{c}{ Dextra } & \multicolumn{2}{c}{ Sinistra } \\
& Jumlah & Persentase & Jumlah & Persentase \\
\hline Normal & 10 & 56 & 8 & 44 \\
Tuli ringan & 8 & 44 & 10 & 56 \\
Tuli sedang & 0 & 0 & 0 & 0 \\
Tuli berat & 0 & 0 & 0 & 0 \\
Total & 18 & 100 & 18 & 100 \\
\hline
\end{tabular}


Tabel 8. Distribusi kebisingan dan fungsi pendengaran

\begin{tabular}{ccccc}
\hline \multirow{2}{*}{$\begin{array}{c}\text { Tingkat } \\
\text { kebisingan }\end{array}$} & \multicolumn{3}{c}{ Fungsi pendengaran } & Uji \\
& Tuli & Normal & Total & $\begin{array}{c}\text { Fisher } \\
\text { exact }\end{array}$ \\
\hline$<85 \mathrm{~dB}$ & 5 & 4 & 9 & \\
$>85 \mathrm{~dB}$ & 8 & 1 & 9 & 0,294 \\
Total & 13 & 5 & 18 & \\
\hline
\end{tabular}

Tabel 8 memperlihatkan bahwa terdapat 2 sel yang memiliki harapan kurang dari 5 yaitu nilai 4 pada tingkat kebisingan $<85 \mathrm{~dB}$ dan memiliki fungsi pendengaran normal serta nilai 1 pada tingkat kebisingan $>85 \mathrm{~dB}$ dan memiliki fungsi pendengaran normal. Karena 2 sel memiliki nilai harapan kurang dari 5 maka uji chi square tidak memenuhi syarat. Oleh karena itu dalam penelitian ini digunakan alternatif lain yaitu uji Fisher exact yang mendapatkan nilai $\mathrm{p}=0,294(\mathrm{p}>0,05)$.

\section{BAHASAN}

Dalam kehidupan sehari-hari pasti kita sering sekali terpapar oleh bunyi baik bunyi yang dikehendaki maupun tidak. Bunyi yang tidak dikehendaki disebut bising. Bising dapat dijumpai di berbagai tempat tidak terkecuali arena bermain yang berisi mesin-mesin permainan penghasil suara. Bising dapat memengaruhi kesehatan bila terdapat faktor-faktor seperti intensitas, frekuensi, lama paparan, dan sensitivitas individu.

Penelitian yang dilakukan oleh Komite Nasional Penanggulangan Gangguan Pendengaran dan Ketulian (Komnas PGPKT) tahun 2012 pada tempat hiburan anak di 16 kota besar di Indonesia mendapatkan hasil intensitas kebisingan rerata yaitu 94,4-128 $\mathrm{dB}^{7}$ Penelitan oleh Tumewu et $\mathrm{al}^{4}$ tahun 2014 di arena bermain Manado Town Square mendapatkan intensitas bising rerata $88 \mathrm{~dB}$ dan $93 \mathrm{~dB}^{4}$ Hal tersebut dapat menimbulkan masalah fungsi pendengaran bila terpapar terus menerus.

Berdasarkan penelitian yang dilakukan di tiga arena bermain di Kota Manado yaitu Amazing Zone Star Square Manado,
Amazone dan Timezone Manado Town Square didapatkan nilai rerata kebisingan berturut-turut $85,4 \mathrm{~dB}, 89,8 \mathrm{~dB}$, dan 85,5 $\mathrm{dB}$ yang telah melebihi batas normal paparan kebisingan yaitu 85 dBA. Perbedaan tingkat kebisingan tersebut dipengaruhi oleh berbagai faktor seperti luas tempat/arena bermain, luas tempat yang terbuka, jenis-jenis permainan, dan tata letak permainan/mesin permainan.

Tingginya tingkat paparan kebisingan tersebut merupakan risiko penyebab gangguan pendengaran sensoris yaitu NIHL yang terjadi karena kerusakan struktur dalam koklea atau hilangnya sel-sel rambut organ korti.

Kebisingan yang menyebab gangguan pada organ korti berupa kerusakan struktur dalam koklea terjadi pada epitel sensori yang terdiri dari satu baris dalam sel-sel rambut stereosilia dan tiga baris luar sel-sel stereosilia didukung oleh sel Hansen dan sel Deiter. ${ }^{8,9}$ Hilangnya kekakukan stereosilia disebabkan oleh perubahan vaskular, kimia, dan metabolisme sel-sel sensorik. Awalnya akan terjadi pergeseran ambang batas sementara dan pendengaran akan pulih seiring berjalannya waktu. Sebaliknya jika paparan berkelanjutan maka akan terjadi pergeseran ambang batas permanen dengan stereosilia yang menghilang permanen, fraktur struktur roulette, dan penghancuran sel sensorik menjadi jaringan parut. Pergeseran ambang batas permanen terjadi karena paparan singkat dengan intensitas tinggi. ${ }^{10}$

Berdasarkan hasil penelitian pada 18 orang karyawan di arena bermain tersebut didapatkan kelompok usia terbanyak yaitu 18-21 tahun sebanyak 10 orang (56\%). 
Lama bekerja $<10$ tahun merupakan yang terbanyak yaitu 17 orang $(94 \%) ; 11$ orang di antaranya memiliki lama kerja $<1$ tahun. Durasi kerja terbanyak yaitu 8 jam sebanyak 15 orang $(83 \%)$.

Sebelum dilakukan pemeriksaan audiometri dilakukan pengisian kuisioner penelitian dan didapatkan bahwa karyawan arena bermain tidak menggunakan alat pelindung telinga, tidak memiliki riwayat trauma telinga, dan tidak memiliki riwayat keluar cairan melalui telinga. Pada pemeriksaan fisik didapatkan MAE dan membran timpani normal pada semua responden. Pada pemeriksaan audiometri untuk menilai fungsi pendengaran terdapat 10 orang normal pada telinga kanan dan 8 orang normal pada telinga kiri, serta 8 orang tuli ringan telinga kanan dan 10 orang tuli ringan telinga kiri. Nilai ambang batas kebisingan yang dianjurkan yaitu maksimal $85 \mathrm{~dB}$ dalam waktu 8 jam sesuai dengan Permenkes No.70 tahun 2016 tentang standard dan persyaratan kesehatan lingkungan kerja industri. ${ }^{2}$

Hasil penelitian ini menunjukkan 2 sel yang memiliki harapan kurang dari 5 yaitu nilai 4 pada tingkat kebisingan $<85 \mathrm{~dB}$ dan memiliki fungsi pendengaran normal serta nilai 1 pada tingkat kebisingan $>85 \mathrm{~dB}$ dan memiliki fungsi pendengaran normal. Karena 2 sel memiliki nilai harapan kurang dari 5 makan uji chi square tidak memenuhi syarat dan digunakan alternatif lain yaitu uji Fisher exact yang mendapatkan nilai $p=0,294(p>0,05)$ yang berarti tidak terdapat hubungan bermakna antara fungsi pendengaran dan derajat kebisingan. Hasil penelitian ini tidak sejalan dengan penelitian yang dilakukan Tumewu et $\mathrm{al}^{4}$ pada arena bermain Manado Town Square dan Manado Trade Center yang mendapatkan hubungan antara tingkat kebisingan dan ambang pendengaran pada karyawan arena bermain. Perbedaan hasil kedua penelitian ini diduga disebabkan karena beberapa hal, yaitu: Lama bekerja dari karyawan arena bermain $<10$ tahun sebanyak 17 orang dan 11 orang diantaranya $<1$ tahun yang menunjukkan lama bekerja yang sangat singkat sehingga tidak didapatkan gang- guan fungsi pendengaran yang berarti. Selain itu tingkat kebisingan pada arena bermain dalam penelitian ini relatif terkontrol sesuai Permenkes No.70 tahun $2016^{2}$ dan kebisingan yang melebihi batas hanya pada permainan tertentu saja seperti pump it up dan dance revolution. Tingkat kepedulian manajer yang cukup tinggi dalam mengontrol bunyi dari setiap mesin permainan yang ada dan tata letak mesin permainan serta durasi kerja yang diberlakukan 8 jam sehari pada 15 orang karyawan untuk pencegahan gangguan fungsi pendengaran akibat bising.

\section{SIMPULAN}

Tidak terdapat pengaruh bermakna dari kebisingan terhadap gangguan pendengaran karyawan di arena bermain. Walaupun demikian, terdapat gangguan pendengaran ringan pada sebagian besar karyawan arena bermain.

\section{Konflik Kepentingan}

Penulis menyatakan tidak terdapat konflik kepentingan dalam studi ini.

\section{DAFTAR PUSTAKA}

1. Keputusan Menteri Negara Lingkungan Hidup Nomor: Kep-48 ... [Internet]. [cited 2019 Aug 27]. Available from: http://web.ipb.ac.id/ tml_atsp/test/Kep men LH 48 Tahun 1996.pdf

2. Supriyadi A. Peraturan Menteri Kesehatan Nomor 70 Tahun 2016 tentang Standar dan Persyaratan Kesehatan Lingkungan Kerja Industri [Internet]. Katigaku.top. 2017 [cited 2019Aug27]. Available from: https://katigaku.top/2017/02/08/ peraturan-menteri-kesehatan-nomor-70 -tahun-2016-tentang-standar-danpersyaratan-kesehatan-lingkungankerja-industri/

3. Barrientos MC, Lendrum DC, Steenland K. Occupational Noise. Environmental Burden of Disease. Geneva: WHO, 2004; p. 9.

4. Tumewu B, Tumbel R, Palandeng OI. Pengaruh bising terhadap ambang pendengaran pada karyawan yang bekerja di tempat mainan anak Manado Town Square. e-CliniC. 2014;2(2).

5. Kementerian Kesehatan Republik Indonesia. 
Nomor 879/Menkes/SK/-XI/2006 tentang Rencana Strategi Nasional Penanggulangan Gangguan Pendengaran dan Ketulian untuk Mencapai Sound Hearing 2030. Jakarta: Kementerian Kesehatan Republik Indonesia, 2006.

6. Rantung R, Lintong F, Danes V. Hubungan bising dengan gangguan pendengaran pada pekerja Game Cenral Area di Area Manado Trade Center. e-CliniC. 2015:3(3).

7. Taba T. Cegah ketulian. akibat bising [Internet]. Komnas PGPKT. 2012 [cited 2019 Aug 27]. Available from: http://komnaspgpkt.blogspot.com/2012/ 10/suara-bising-ancaman-ketulianbagaimana.html

8. Stach BA. Clinical Audiology: an introduction (2nd ed). San Diego, CA: Plural Publishing Inc, 2016; p. 101-9.

9. Flint PW, Haughey BH, Lund VJ. Cummings Otolaryngology (6th ed). Philadelphia, PA: Elsevier, 2015; p. 1994-9.

10. Lalwani AK. Current Diagnosis \& Treatment in Otolaryngology: Head \& Neck Surgery (2nd ed). New York: McGrawHill Medical, 2007; p. 732-5. 